\title{
First record of Lower Triassic Undichna spp. fish swimming traces from Emei, Sichuan Province, China
}

\author{
LU TingQing*, WANG ZhanLei, YANG XiYan \& ZHANG XiaoLi \\ School of Resources and Environmental Engineering, Southwest Petroleum University, Chengdu 610500, China
}

Received October 8, 2011; accepted January 7, 2012; published online February 7, 2012

\begin{abstract}
We discuss traces from the ichnospecies Undichna unisulca recorded from the Triassic that are reported for the first time in this paper. These fossils are also some of the oldest vertebrate ichnites discovered in China to date. The fish swimming traces (Undichna unisulca) described originate from the Lower Triassic. These traces were found in the Jialingjiang Formation and are located at a gorge $\sim 7.5 \mathrm{~km}$ from Emei, Sichuan Province, China. The ichnospecies Undichna unisulca consists of a regular sinusoidal wave. The wavelengths and amplitudes are quite constant between each specimen ranging between 28-32 $\mathrm{mm}$ and 9-12 $\mathrm{mm}$, respectively. The fish swimming traces and distribution within the same bed are preserved as hypichnial ridges at the undersurface.
\end{abstract}

fish swimming trace, Undichna unisulca, Lower Triassic, Jialingjiang Formation, Emei, Sichuan Province

Citation: $\quad$ Lu T Q, Wang Z L, Yang X Y, et al. First record of Lower Triassic Undichna spp. fish swimming traces from Emei, Sichuan Province, China. Chin Sci Bull, 2012, 57: 1320-1324, doi: 10.1007/s11434-012-4980-y

The swimming habits and buoyancy of most fish mean that it is unusual for them to contact bottom substrate such that their swimming traces are preserved. Different species of the ichnogenus Undichna, have been recorded in Devonian to Quaternary strata in many countries since it was first reported in material from the Lower Permian in South Africa [1]. Their morphological features, ichnospecies erection, stratigraphical and geographical distribution, environmental analysis and trace makers analysis have been previously reviewed [2-4]. The ichnogenus found in different sedimentary environments from the Triassic are also well documented, including the Upper Triassic lacustrine environments of Argentina [5], the Lower and Middle Triassic marine-continental transition in Utah, the United States [6] and Italy [7], respectively. In the Middle Triassic, this ichnogenus was found in the marine carbonate flats of Germany [8] and from the Upper Triassic, in lacustrine environments of Shaanxi $[9,10]$. In the Lower Triassic these fossils were found in a carbonate ramp in Guizhou [11].

*Corresponding author (email: lutingqing@ swpu.edu.cn)
In the summer of 2011, during an undergraduate geological fieldtrip in the Emei area, the ichnospecies Undichna unisulca was found at Member 1 of the Jialingjiang Formation of the Lower Triassic. This is the first time that $U n$ dichna unisulca has been recorded in the Triassic and is also one of the oldest vertebrate ichnites discovered in China to date.

\section{Geological setting}

The Lower Triassic Longmendong section (GPS co-ordinates $29^{\circ} 33^{\prime} 47^{\prime \prime} \mathrm{N}, 103^{\circ} 22^{\prime} 59^{\prime \prime} \mathrm{E}$ ), has previously uncovered fish swimming traces from the outcrops at the gorge $\sim 7.5 \mathrm{~km}$ from Emei, Sichuan Province (Figure 1). This section is the part of the northeast flank of a subsidiary anticline (Niubeishan anticline) of the regional Emei great anticline which plunges to the northeast. The outcrop successively stretches $\sim 1.5 \mathrm{~km}$ along the eastern side of the Longmendong River. The tilt beds, dipping northwest, are almost upright on a slight even inversion. In this section are complete strata sequences and 


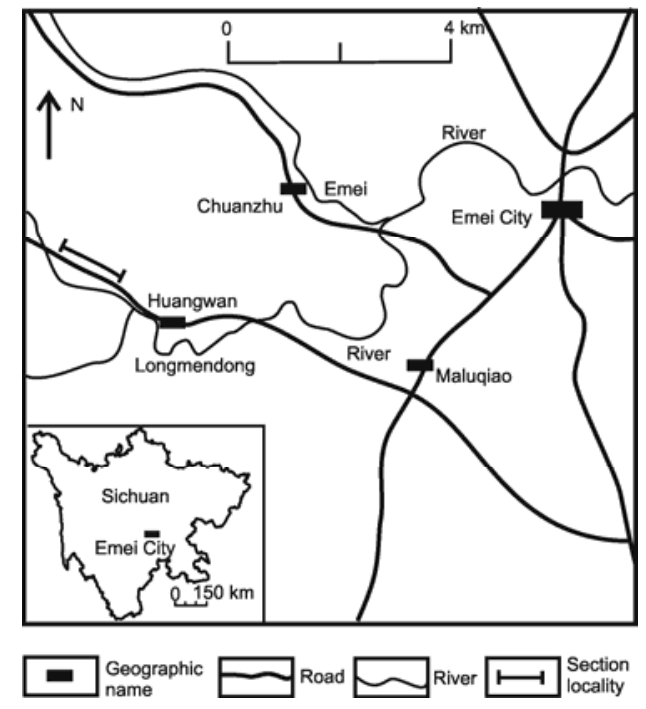

Figure 1 Locality of the Longmendong Section at Emei, Sichuan.

abundant sedimentary facies indicators. Therefore it is an ideal section for examining sedimentary facies and has been protected by the Sichuan government since 1984 .

Triassic strata at the Longmendong section consists of the Feixianguan Formation and Jialingjiang Formation of the Lower Triassic, the Leikoupo Formation of the Middle Triassic, the Kuahongdong Formation, Xiaotangzi Formation and the Xujiahe Formation of the Upper Triassic from northwest to southeast. Among those, the Lower and Middle Triassic strata are significant in this section. The Jialingjiang Formation, in the middle part of the Longmendong section, is about $244 \mathrm{~m}$ thick, and composed mainly of marine carbonates, terrigenous clastics and anhydrites. It is divided into four members by different lithofacies: Member 1 is $~ 90$ $\mathrm{m}$ thick, and is an interbed of grey-green, grey-purple medium- to thinly-bedded fine-grained lithic arenites, siltstones, muddy siltstones and grey calcarenites, bioclastic limestones, oolitic limestones. Member 2 is $41 \mathrm{~m}$ thick, and is an assemblage of purple and grey dolomites, calcareous dolomites, mudrocks intercalated with purple fine- and medium-grained lithic arenites and pebbled arenites. Member 3 is $\sim 56 \mathrm{~m}$ thick, composed of different thicknesses of light grey dolomitic limestones and clayed limestone. Finally, member 4 is $\sim 55 \mathrm{~m}$ thick, and is together with the grey to yellow-brown dolomites intercalated with gypsum karst breccias.

The fish swimming traces are preserved in Member 1 of the Jialingjiang Formation. This contains abundant sedimentary structures and ichnites, and a few foraminifera, bivalve and brachiopods [12-14]. Members 1 and 2 are also from an estuary sedimentary environment $[14,15]$.

\section{Systematic paleontology}

Ichnogenus: Undichna Anderson, 1976.
Diagnosis: The fossil trace marks either comprise of a single horizontal wave, or a set of horizontal waves with a common wavelength and direction of travel. Those waves may be paired, parallel or unpaired. The unpaired waves may be either intertwined or separated. All waves may be continuous or with just troughs or crests preserved. The waves may also be superimposed upon a straight, continuous furrow or ridge. A pair of straight, parallel grooves or ridges may also accompany the waves [3].

Ichnospecies: Undichna simplicitas Anderson 1976; $U$. insolentia Andenson 1976; U. bina Anderson 1976; U. britannica Higgs 1988; U. consulca Higgs 1988; U. radnicensis Turek 1989; U. tricosta Lu \& Chen 1998; U. unisulca Gibert et al. 1999; U. quina Trewin 2000; U. gosiutensis Gibert 2001; U. westerbergensis Schweigert 2001; U. prava Lu et al. 2004; U. trisulcata Morrissey et al. 2004; U. septemsulcata Wisshak et al. 2004.

Locality: South Africa, England, Scotland, Wales, Czech Republic, Norway, Germany, Spain, Austria, Italy, Canada, United States, Argentina, Peru, Australia, China.

Geological age: Devonian-Pleistocene [2,3].

Undichna unisulca Gibert et al. 1999 figure 2

1999 Undichna unisulca Gibert et al. [16] p. 415-419, text-figure 4; plate 1, figures 1-4

2000 Undichna unisulca Gibert et al. 1999; Trewin N H [2], p. 981, text-figure 1

2001 Undichna unisulca Gibert et al. 1999; Soler-GijÓn \& Moratalla [17], p. 13-15, figure 7

2004 Undichna unisulca Gibert et al. 1999; Morrissey et al. [18], p. 342-344, figure 4

2006 Undichna unisulca Gibert et al. 1999; Minster \& Braddy [3], p. 1132-1133, text-figure 2R

Material: Three specimens are preserved in situ on the reverse bedding plane. As this is a geological protected profile we were unable to collect any specimens. Instead, field photos were taken (see Nos 100-6285 and 100-6286). We found two well preserved specimens within the hyporeliefs of the undersurface bedding.

Diagnosis: The trace is a hyporelief consisting of a single symmetrical sinusoidal wave.

Description: The Undichna unisulca fossil is in the form of a sinusoidal wave. The first wave (No. 1) is of regular symmetrical shape and $87 \mathrm{~mm}$ in length. The second wave (No. 2) is slightly asymmetrical and $62 \mathrm{~mm}$ in length. The third wave (No. 3) appears to be half of a sinusoidal wave where two ends of the trails disperse naturally on the undersurface (Figure 2(a),(b)). The wavelengths range between 28-32 $\mathrm{mm}$ and the amplitude varies from 9 to $12 \mathrm{~mm}$. The average ratio amplitude/wavelength $(A / \lambda)$ is $\sim 0.32$. Both the wavelength and amplitude are constant in each of the specimens we studied. The fish swimming traces are all preserved as hypichnial ridges from the same bed. The ridge from the No. 1 wave is $2 \mathrm{~mm}$ wide, whereas, that from No.2 is $1.5 \mathrm{~mm}$. The width of these ridges is relatively constant and the two flanks show slight symmetry with respect to 

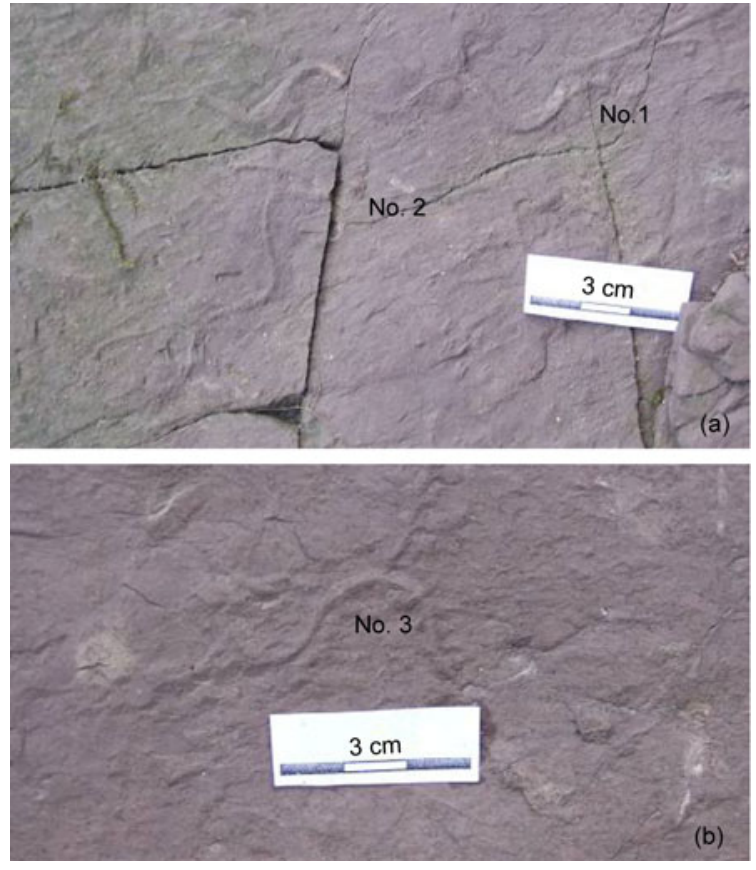

Figure 2 An example of a typical field photograph of Undichna unisulca. (a) Two solitary fossils, Nos. 1 and 2 (photo number 100-6285); (b) one fossil, No. 3 (photo number 100-6286). All fossils were preserved on the undersurface.

height of $\sim 1 \mathrm{~mm}$, but without accompanying lateral grooves or levees.

Comparison: These traces match the morphology of the specimen Undichna unisulca described by Gibert et al. [16]. Those specimens were from Spain and were Cretaceous in age but without sharply incised grooves or corresponding hypichnial ridges. Their hypichnial ridges were narrower and lacked the shallow central furrow (refer to text and Figure $4 \mathrm{c}[16,18])$. The wavelength and amplitude of the traces we found were more constant and had more regular symmetry than those specimens described by Gibert et al. [16], Morrissey et al. [18] and Soler-GijÓn et al. [17]. However, the former were smaller in dimension and shorter in length than the latter. The ratio amplitude/wavelength $(A / \lambda)$ was approximately twice that compared to the specimens described by Gibert et al. [16] and Morrissey et al. [18].

Discussion: The fossil Undichna unisulca encountered in Gibert et al. [16] was unlikely to be the same undertrail of the species of Undichna isp in our samples which is generally more complex. Undichna unisulca from Member 1 in the Jialingjiang Formation of Longmendong Section was assumed as there was no other species like Undichna britannica (Higgs, 1988) that had group of regular sinusoidal waves within this member [3]. Several determined and undetermined species of Undichna in the Triassic strata have been found in Italy [7], the United States [6], Argentina [5], Germany [8], and Shaanxi [9,10] and Guizhou [11], China. However, only our specimens have been documented from the Triassic at this section. Cochlichnus and Undichna uni- sulca, as eurytopic trace fossils, share the similar sinusoidal horizontal burrows and sedimentary environments, yet the sinusoidal wave of Cochlichnus is sharper and the color of the filled materials in their burrows are generally different from the host rock [19]. Cochlichnus anguineus (Hitchoock, 1858) (see Figure 4e in text [14]) was also observed in the same member of the Jialingjiang Formation, Emei which shows an obvious burrow.

Locality and horizon: The Member 1 location is at the Jialingjiang Formation, Lower Triassic, Longmendong gorge in Emei city, Sichuan Province.

\section{Analysis of paleoenvironments and fish swimming traces}

Undichna mostly appears in the terrestrial sedimentary beds [16], particularly in lake deposits [4]. However, in more recent years, more have been found within marine deposits $[5,7,8,17]$. Our samples were different from the abundant Undichna in carbonate tidal flat environments of the west Germanic Basin in the Middle Triassic [8]. Our Member 1 sample in the Jialingjiang Formation, Emei region was the product of an estuary sedimentary environment [14,15] accompanied with a middle tidal range [15]. The taphonomic conditions that favor the production and preservation of Undichna were suggested by Gibert et al. [16] and include: (1) absence or scarcity of infaunal burrowers, (2) very finegrained sediment in plastic or semi-consolidated state, (3) low-energy conditions near the bottom, and (4) relatively rapid burial without associated erosion. Environments such as lakes, alluvial swamps and the inner rim of estuaries, favor the preservation of Undichna. Moreover, in recent work, Gibert [20] pointed out that the preservation of $U n$ dichna was favored in association with invertebrate trace fossils. These were usually shallow-tier and epigenic traces, indicated by the Mesozoic and Cenozoic Undichna and inferred an oxygenated and dysoxic environment such as the boundary close to or at the sediment-water interface. However, many trace fossils are produced at the Member 1 site including mostly endogenic traces [12,14] followed by epigenic traces and other vertebrate traces were lacking. Many of the sedimentary structures are parallel/horizontal laminations, flaser, lenticular and wavy beddings, load casts, scours and channels, desiccation cracks, ripples and deformed bedding that are accompanied in the beds. The rocks containing Undichna unisulca are dark purple, thin-bedded, calcium mud bearing siltstones, banded by sandy silt stripes. The grains were fine and the sedimentary geography was flat, probably indicating shallow water conditions and semiconsolidated sediments when the Undichna unisulca fossils were formed.

The symmetry, constant wavelength and amplitude of the three specimens of Undichna unisulca sinusoid waves studied were not parallel and not superposed to each other at 
Member 1. This suggests that the water environment was relatively shallow and hydrostatic. The asymmetrical sinusoidal wave was probably caused by the orientation of the fish swimming differently to that of the water current. Whether the wavelength got bigger or smaller and the amplitude got smaller or bigger at the same wave was probably because the fish was headed down or up the current [2] or because of the change in the fish swimming speed (acceleration or deceleration) [17]. Therefore, it is suggested that Undichna unisula ichnospecies found in Member 1 of the Jialingjiang Formation, Emei, were created from fish that swam at a constant speed, within a low, relatively shallow, substrate with weak energy water during an ebb tide within an estuary.

Using the 10-mm-wide sinusoidal wave amplitude, we suggest it was formed by the caudal fin of the fish and that the fish's length was ca. four times the amplitude [21]. Thus, we can deduce the fish's body was about $40 \mathrm{~mm}$ in length. Restoration of the trace marks of the swimming fish are based on fish fossils in the same age strata [16,17,21,22]. Gibert et al. [16] suggested the Undichna unisulca ichnospecies was produced by the anal fin of Macromesodon aff. bernissartensis that has a discoidal, laterally flattened body. This swimming trace is probably the trajectory of the fish, and not the thrusting impulses of the caudal fin. Scarcity of fish fossils from the Lower Triassic in the Sichuan Basin and the Upper Yangtze region increases our difficulty in reconstructing early Triassic fish marks. Fortunately, there are abundant fish fossils from the Middle and Lower Yangtze region [23-26], especially in Jurong of Jiangsu Province. These Perleidus fish fossils are widely distributed and have dominant characteristics such as larger anal and caudal fins $[27,28]$. We therefore suggest that it is possible that the Undichna unisulca ichnite produced a trace mark from the lower lobe of the caudal fin, similar to that of Perleidus fish.

Abundant vertebrate ichnites were distributed in the Mesozoic and Cenozoic era in China, but most are reported from vertebrate ichnites from the Late Triassic including dinosaur tracks and fish swimming traces [9,29]. There are not many reported vertebrate ichnites earlier than the Late Triassic. The Undichna unisulca ichnospecies was found at Member 1 of the Jialingjiang Formation, Emei Region of Sichuan Province. Together with the same era (early Triassic) Undichna isp. found at Member 2 of the Daye Formation in Guiyang city, Guizhou Province [11] and the Undichna-like traces from the Nanlinghu Formation, Chaohu, Anhui Province [30], these fossils represent the oldest evidence of vertebrate ichnites in China.

\section{Conclusions}

We discovered the fossil of Undichna unisulca, one of the oldest vertebrate ichnites found in China. This is the first time this ichnospecies has been found dating back to the Triassic Period. The fish swimming trace markers were from Perleidus fish, formed in an environment of mixed sedimentation of terrigenous clastic and carbonate flats within a middle tidal range estuary.

This work was supported by the Sichuan Key Discipline Constructing Project (SZD414) and the Sichuan Education Reform Project (P09162). We are grateful to Liu Tingyuan of the Library of Southwest Petroleum University and Dr. Xu Qiang of the Institute of Tibetan Plateau Research of the Chinese Academy of Sciences for providing some valuable foreign material. We are also grateful to anonymous reviewers for their constructive comments on improving this paper.

1 Anderson A. Fish trails from the Early Permian of South Africa. Palaeontology, 1976, 19: 397-409

2 Trewin $\mathrm{N} \mathrm{H}$. The ichnogenus Undichna, with examples from the Permian of the Falkland Islands. Palaeontology, 2000, 43: 979-997

3 Minter N J, Braddy S J. The fish and amphibian swimming traces Undichna and Lunichnium, with examples from the Lower Permian of New Mexico, USA. Palaeontology, 2006, 49: 1123-1142

4 Seilacher A. Trace Fossils Analysis. Heidelberg: Springer-Verlag, 2007. 226

5 Melchor R N, Cardonatto M C. Pistas de peces (Undichna): Rango estratigrafico, paleoambientes y mecanismos de propulsion del productor. Tercera Reunión Aegentina de Ichnologia, Primiera Reunión de Ichnologia del Merosur. 1998. 20-21

6 Mickelson D L, Huntoon J E, Kvale E P. The diversity and stratigraphic distribution of Pre-dinosaurian communities from the Triassic Moenkopi Formation, Capitol Reef National Park and Glen Canyon National Recreation Area, Utah. Geol Soc Amer Abst Prog, 2005, 37: 40

7 Todesco R, Avanzini M. First record of the fish trace fossil Undichna from the Middle Triassic of Italy. Studi Trent Sci Nat Acta Geol, 2008, 83: 253-257

8 Diedrich C. Vertebrate track bed stratigraphy at new megatrack sites in the Upper Wellenkalk Member and orbicularis Member (Muschelkalk, Middle Triassic) in carbonate tidal flat environments of the western Germanic Basin. Palaeogeogr Palaeoclimat Palaeoecol, 2002, 183: $185-208$

9 Lu Z S, Chen B. Discovery of Late Triassic fish trails (Undichna) in Hengshan County, Shaanxi, China (in Chinese). Acta Palaeontol Sin, 1998, 37: 76-85

10 Lu Z S, Hao Z K, Chen B, et al. New evidences of Late Triassic fish swimming traces in Hengshan County, Shaanxi Province, China (in Chinese). Acta Palaeontol Sin, 2003, 42: 266-276

11 Luo M, Shi G, Gong Y M. Early Triassic trace fossils in Huaxi region of Guiyang and their implications for biotic recovery after the end-Permian mass extinction (in Chinese). J Palaeogeogr, 2007, 9: 519-532

12 Lin W Q, Wang H F, Song H B. Upper Permian to Lower-Middle Triassic strata and sedimentary environments in Longmendong, Emei, Sichuan (in Chinese). J Min Petrol, 1982, 3: 50-55

13 Wang Z Y, Deng J H. Tidal flat deposit of Lower Triassic Jialingjiang Formation in Emei Longmendong, Sichuan (in Chinese). J Min Petrol, 1982, 3: 83-93

14 Zhang G C, Wang K. Ichnofabrics and their sedimentary significance of Member 1 of Lower Triassic Jialingjiang Formation at Longmendong, Emei Mountains, Sichuan Province (in Chinese). J Palaeogeogr, 2010, 12: 281-290

15 Liu B J, Zen Y F. Lithofacies Palaeogeographical Basis and Its Researching Methods (in Chinese). Beijing: Geological Publishing House, 1985. 442

16 Gibert J M, Buatois L A, Fergenal-Martinez M A, et al. The fish trace fossil Undichna from the Cretaceous of Spain. Palaeontology, 1999, 42: 409-427

17 Soler-Gijón R, Moratalla J J. Fish and tetrapod trace fossils from the Upper Carboniferous of Puertollano, Spain. Palaeogeogr Palaeocli- 
mat Palaeoecol, 2001, 171: 1-28

18 Morrissey L B, Braddy S J, Bennett J P, et al. Fish trails from the Lower Old Red Sandstone of Tredomen Quarry, Powys, southeast Wales. Geol J, 2004, 39: 337-358

19 Yang S P, Zhang J P, Yang M F. Trace Fossils of China (in Chinese). Beijing: Science Press, 2004. 353, Plate 64

20 Gibert J M. Undichna gosiutensis, isp. nov.: A new fish trace fossil from the Jurassic of Utah. Ichnos, 2001, 8: 15-22

21 Higgs R. Fish trails in the Upper Carboniferous of Southwest England. Palaeontology, 1988, 31: 255-272

22 Wang L F, Lu Z S, Gong D H, et al. Restoration of Late Triassic fish trace makers in Hengshan County, Shaanxi Province, China (in Chinese). Earth Sci-J Chin Univ Geosci, 2008, 33: 12-18

23 Su D Z. A new species of Perlerdus from Anhui (in Chinese). Vert Palas, 1981, 19: 107-112

24 Su D Z, Li Z C. A new Triassic Perleidid fish from Hubei, China (in Chinese). Vert Palas, 1983, 21: 9-16

25 Jin F, Wang N Z, Cai Z Q. A revision of the Perleidid fishes from the
Lower Yangtze Region of South China-Second report on the fish sequence study near the Permian-Triassic boundary in South China (in Chinese). Vert Palas, 2003, 41: 169-184

26 Zhao L J, Lu L W. A new genus of Early Triassic Perleidid fish from Changxing, Zhejiang, China (in Chinese). Acta Palaeontol Sin, 2007, 46: $238-243$

27 Qian M P, Zhu S P, Zhao F M, et al. Discovery of Early Triassic fish fossils and its significances injuring, Jiangsu Province (in Chinese). Jiangsu Geol, 1997, 21: 65-71

28 Liu G B, Feng H Z, Wang J X, et al. Early Triassic fishes from Jurong, Jiangsu (in Chinese). Acta Palaeontol Sin, 2002, 41: 27-52

29 Gong Y M, Hu B, Lu Z S, et al. Study of trace fossils in the past eighty years in China (in Chinese). Acta Palaeontol Sin, 2009, 48: 322-337

30 Chen Z Q, Tong J N, Fraise M L. Trace fossil evidence for restoration of marine ecosystems following the end-Permian mass extinction in the Lower Yangtze region, South China. Palaeogeogr Palaeoclimat Palaeoecol, 2011, 299: 449-474

Open Access This article is distributed under the terms of the Creative Commons Attribution License which permits any use, distribution, and reproduction in any medium, provided the original author(s) and source are credited. 